\title{
The Long Tail Outcomes Summarised
}

The 10 stories demonstrate that conferences are shared social contexts which take people away from their established routines. Within this social context, knowledge and ideas are shared and common goals are developed through such interactions. It is not surprising then that these stories demonstrate a direct connection between the staging of conferences and an extensive range of benefits and outcomes beyond the tourism spend.

In previous work we have argued that the benefits and outcomes have impact in five broad areas: intrinsic, practice, social, economic and attitudinal (Edwards et al. 2011). As indicated in Table 1, overleaf, the legacies are not mutually exclusive - a benefit or outcome may have multiple legacies.

Intrinsic legacies are the personal outcomes delegates gain to develop their knowledge and skills. In the collaborative environment of the business event they are able to express and share their knowledge, skills and practices with a broad range of people including peers, colleagues, and others who may come from industry, government and not-for-profit organisations. Related to this are social legacies, which represent the camaraderie that develops around the conference, the appeal of engaging with other like-minded people, the relationships that are enhanced and developed, and the broader benefits that accrue to the communities in which the conference is held. Business events develop a social space that is important as it facilitates and reinforces social interaction and, in turn, influences the effectiveness of collaborative learning. Tacit knowledge can be spread through informal interactions with current and new colleagues.

Professional and practice legacies result from the skills and knowledge that delegates gain - such as attaining new insights, learning surgical techniques, sharing new ideas and identifying solutions to solving problems - being directly integrated into their professional practices and organisations. Professional legacies also arise for the delegate from gaining business partners, building research networks and obtaining knowledge that can solve research and business problems. 
Attitudinal legacies arise from the reactions of delegates to their experiences at the conference, and from governments, the private sector and individuals who become aware of important issues that are communicated through the international and local media.

Economic legacies are realised as social networks affect the flow and the quality of information. Moving in different circles from one's own group connects people to a wider world and therefore any new acquaintances can be better sources of information as delegates go beyond what their own group knows. As conferences are intense periods during which social interaction is fostered, they lead to benefits and outcomes that have both intangible and tangible economic effects, such as building knowledge and capabilities, identifying business partners, improved workforce practices, better education, new investments, enhanced funding and better industry sector policies. 
Power Of Conferences

TABLE 1 BENEFIT AND OUTCOME LEGACIES ARISING FROM BUSINESS EVENTS

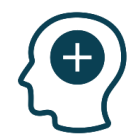

INTRINSIC

\section{$i$ \\ PROFESSIONAL PRACTICE}

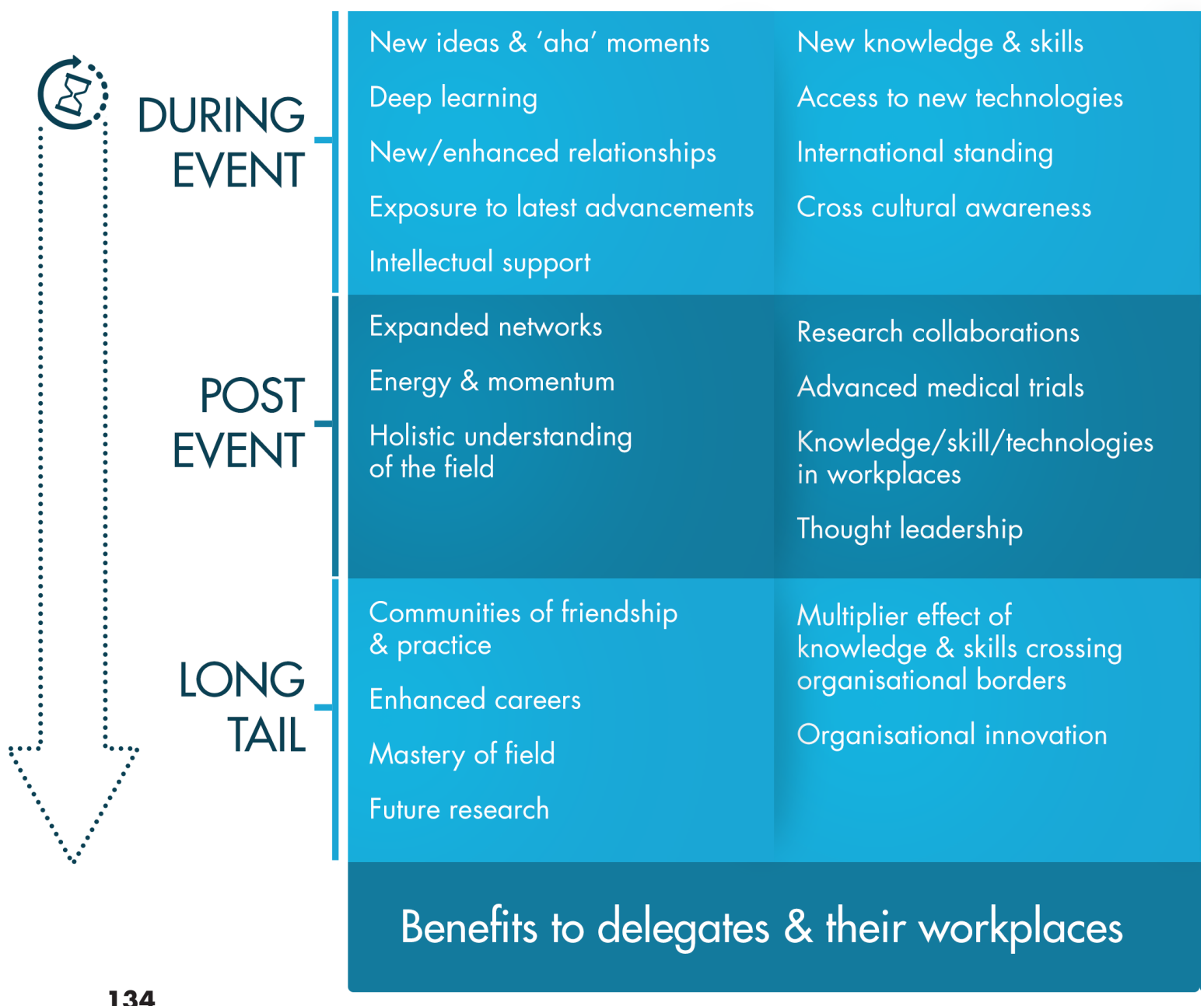


Long Tail Outcomes Summarised

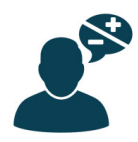

ATTITUDINAL

Media/publicity

Enhanced destination reputation

Making science relevant

Influence on public perception

\section{ECONOMIC}

Tourism contribution

Academia \& industry

partnerships/investment
Energised industry sectors

Raised awareness of sector

Government/community support
New/enhanced avenues of investment \& trade

Community benefit from enhanced business practice
Positive social change

Policy development
Industry innovation

Product development

Medical breakthroughs

Scientific discovery

Thriving economies

\section{Benefits to communities, industry sectors \& economies}

